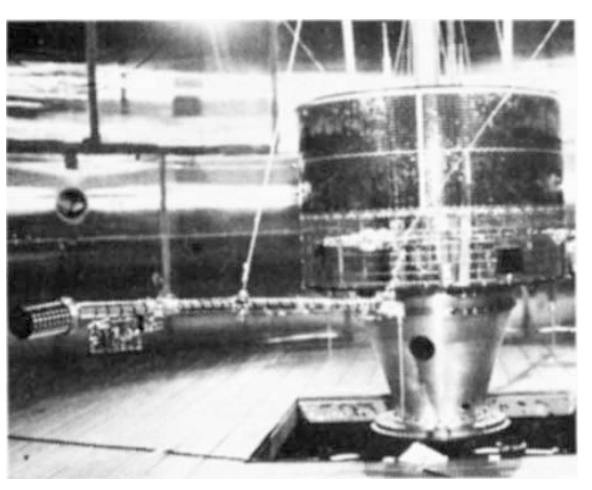

Geos 2 in

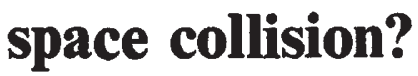

ESA's geostationary magnetospheric observatory satellite Geos 2 (above) appears to have suffered a collision in space. While the performance of much of the payload is unaffected, experiments studying the low energy plasma have been badly disturbed.

Geos 2, a replacement for Geos 1 which was lost in an aborted launch last year, became fully operational on 2 August. With all the onboard instruments functioning well, the prospects for a full two-year mission were excellent until 07.13 GMT on 5 August, when there was a temporary loss of UHF telemetry. The fault proved to be serious for the low energy plasma experiments, as it now seems that the electrical reference potential of the spacecraft is jumping by 12 volts for half of each 6-second spin cycle. It appears that damage to a small section of one solar array panel has resulted in the output of a string of cells shorting to the structure whenever they become illuminated.

There is now a whole catalogue of anomalies seen on high altitude satellites. It is fashionable to assume that they result from spacecraft charging events but, in the case of Geos 2 there are good reasons for lonking clscuhere. Cieos was carefully designed to eliminate differential charging: the solar cells have a conductive indium oxide coating and indeed this could provide the supposed shorting path if severe mechanical damage was experienced.

Well over a hundred spacecraft are now in geostationary orbit but there is no account of how many sensor covers, boom retaining clamps, attachment rings etc. have been ejected. Unlike cans thrown from cars along the road, they are sure to bounce back.

In the future, space shuttle may provide the needed 'vacuum cleaner' but in the meantime the warning is clear. The Geostationary corridor is filling rapidly and spacecraft designers must become litter conscious or risk the consequences.

Gordon Wrenn

\title{
UNCSTD: a ray of hope despite delay in planning
}

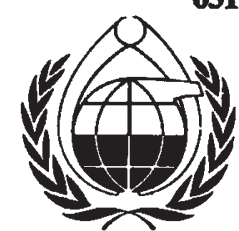

AN unexpected, faint, note of optimism was apparent in recent talks with Guy Gresford, Deputy to José da Costa, the Secretary General of the UN Conference on Science and Technology for Development (UNCSTD). This was surprising, because Gresford had just heard of the postponement by the Economic and Social Council (ECOSOC) of the third Preparatory Committee meeting of the Conference, from 18 September, to January 1979. So that fourth and final preparatory meeting, scheduled for next February, will now take place in May, only three months before the Conference itself. The wise arrangement of leaving six clear months for the final Conference preparations goes by the board: scarcely three months will now be available for the diplomatic negotiations with governments, particularly the "Group of 77" (now in fact 114) which are essential if UNCSTD is to be anything more than just another political confrontation.

It was the " 77 " who used their voting majority to obtain the postponement at the recent ECOSOC meeting in Geneva. Their reasons are not quite clear. One was allegedly the short time between the Conference on Technical Cooperation between Developing Countries (TCDC) in Buenos Aires later this month, and the September meeting. More likely, perhaps, is a feeling of frustration at the lack of any output from the Conference Secretariat worth discussing in September, and a general disillusion of the "77" (in addition to that earlier felt by other groups) at the performance of da Costa himself as Secretary Genera1. In sharp contrast to Maturice Strong during the preparations for the Stockholm Linvironment Conference, da Costa has visited few member states, and been seen in few developing countries. Indeed, he has seldom apparently been seen around his own secretariat in New York, living as he has been mostly in Paris.

From the first, da Costa made it clear that the material for his Conference should come from member governments, especially (but perhaps optimistically) from the "77". But most of the latter need some guidance as to what is expected of themsomething to chew on before they commit themselves. This has been notably lacking. It could have come from the UN Specialised Agencies, but these da Costa antagonised almost from the start. It might have come from within UN itself, but his refusal to work with the Office for Science and Technology in New York made that impossible. But quite apart from this, the fact is that the whole UN system has become grossly overloaded by the ever-increasing number of meetings and conferences to be serviced, against continuing demands for economy and reduction of staff. One European delegate remarked that he would spend 40 of the next 52 weeks attending meetings of one sort or another: that is bad enough for a big delegation, but for countries that can barely raise more than a single representative even for an important meeting, it is intolerable.

Paradoxically, this very delay may add a little more to Gresford's cautious optimism, by giving more time to prepare for the next preparatory meeting, and in particular, to study the national papers which are the basic material for the main Conference background documents. Some 90 national reports had been received by the 1 August deadline, with presumably a few stragglers to come in. It is the quality, as well as the number, of those from the developing countries that have brought a ray of cheer to the hard-pressed secretariat; in particular, several of the least-developed and poorest countries have produced good papers-perhaps because they are among those to whom the services of over 50 special advisers have been provided in one way or another. This should make it easier to prepare the Action Plan for the Conference, always provided that governments will support, at the diplomatic level next year, what they have said in their pre-conference submissions. It is on this that the success or laailure of the Conference depends, since the aim all along has been to avoid confrontation between North and South-in effect, between the " 77 " and restby having the recommendations and Action Plan agreed in advance, leaving the meeting itself for political speeches.

Meanwhile, the effect of the postponement will be felt all along the line. What is unlikely, however, is that the Conference itself will be postponed. As the first really big event held under Kurt Waldheim's Secretary Generalship in his own country, it is a matter of prestige for him that it will go according to plan, and any change of dates seems out of the question, quite apart from what the Austrian Government might have to say about a request for postponement.

Peter Collins 